\title{
Socio-economic and Demographic Determinants of Women's Household Decision Making Autonomy in Bangladesh: A Cross-sectional Study
}

\author{
Kanchan Kumar Sen*, Mirajul Islam and Muhammad Mahmudul Hasan \\ Department of Statistics, Dhaka University, Dhaka-1000, Bangladesh
}

(Received: 29 March 2018; Accepted: 12 June 2018)

\begin{abstract}
Women's autonomy is an important element of the economic and reproductive health developments in a country. The aim of this study was to find out the potential factors associated with women's decision-making autonomy in Bangladesh. To fulfill this purpose, the cross-sectional data obtained from the Bangladesh Demographic Health Survey (BDHS), 2014 was used. The generalized linear mixed model approach has been applied to calculate the adjusted effects of the covariates by taking into account the correlation among subjects within clusters. The study reveals that women with age at marriage $\geq 18$ years, having family size $\leq 4$, having at least one child, exposed to media, belonging to NGO, living in urban areas and working outside home have greater influence on autonomy in household decision making.
\end{abstract}

Keywords: Autonomy, Mixed logistic regression, BDHS, Adjusted odds ratio.

\section{Introduction}

Empowerment was broadly defined as the "expansion of freedom of choice and action". Women's empowerment is a prior condition for women's autonomy. It is difficult to quantify the term autonomy in words easily ${ }^{2}$. It is actually the freedom of one's wish and ability of an individual to work separately without influence of others. Autonomy points out the technical, social, and psychological capability of gaining information and using these information to make own decisions about one's private concerns and one's intimates ${ }^{3}$. It creates ability of a woman to control fertility level as well as awareness about child nutritional level with maternal and child health care. Decision making power of a woman is become greater when a woman has access to do work outside the home ${ }^{4}$. The validated capability of women to take part in decision-making, control over financial resources as well as freedom of movement has been considered as women's autonomy recently ${ }^{5}$.

Though women's autonomy is necessary for the development of a country, women's autonomy level in Bangladesh is very low ${ }^{6}$. Maternal healthcare in Bangladesh for antenatal care and postnatal care increases by 0.14 unit and 0.13 unit, respectively for one unit increase in women's autonomy ${ }^{7}$. The use of modern contraceptive was found to be positively associated with household level decision making in Bangladesh ${ }^{8-9}$. A study using BDHS, 2007 data observed that $33 \%$ currently married women but nonpregnant in Bangladesh were not participated in family decisions and out of them $51.1 \%$ were not using any modern method of contraception ${ }^{10}$. This study also assessed strong attachment among women autonomy with modern contraceptive use and future intention. A random study on married women was conducted in Bangladesh and the study revealed strong interrelation among controlling reproduction, sexual behavior index, reproductive behavioral index with women's autonomy ${ }^{11}$. These findings suggest that women autonomy is a crying need for the well management of reproductive health in Bangladesh. So it is important to find out the factors associated with women autonomy in Bangladesh so that necessary steps can be taken to increase the autonomy level of women.

A number of variables such as education level of women, employment status, household income and spousal age difference were considered as covariates for women's autonomy in taking decision about health care services ${ }^{12-13}$. A study using data from the Matlab Health and Socio Economic Survey found that wage income had a greater effect on women's autonomy in rural Bangladesh than the return obtained from unearned income ${ }^{14}$. Several studies conducted in different countries found that women's autonomy was significantly positively related to pregnancy and delivery care ${ }^{15-17}$, increasing rate of child nutrition ${ }^{18}$ single marriage and consciousness about health matters ${ }^{19}$. It was also observed that unintentional pregnancy, higher fertility were negatively associated with women's autonomy $^{20-21}$.

In this study, we have used the BDHS, 2014 data to find out the potential determinants that influence women's autonomy in Bangladesh directly or indirectly. Since data were collected within 600 clusters, it is assumed that the subjects within the clusters are correlated. To take this correlation into account, mixed logistic regression model is applied to obtain more precise and efficient estimates of the parameters.

\section{Data and Methodology}

\section{Data}

In this study we have conducted secondary analysis based on the BDHS, 2014 data. The two-stage stratified sampling has been used in BDHS, 2014. The total of 600 enumeration areas (EA) were selected in the first stage which are the clusters, and then a systematic sampling was used in the second stage of sampling to get 30 households from each EA and hence the BDHS, 2014 data consists of 17,863 women respondents ${ }^{25}$. We selected 16,545 women aged 15-49 instead of total interviewed women 17,863 because of some missing observations of the selected variables in the study. 


\section{Response and Independent variables}

Women's autonomy on household decision-making was measured based on individual questions regarding who took decisions in the household. There was four questions in BDHS, 2014 data with six options of response. The options of the questions were: (1) respondent alone, (2) respondent and husband/partner, (3) respondent and other person, (4) husband/partner alone, (5) someone else, (6) other. To create the response variable, firstly a value of 1 was assigned if the answer of the questions was (1), (2) or (3), and 0 was assigned for (4), (5), or (6). The values were then aggregated resulting in a score from 0 to 4 . Finally, to create the binary variable women's autonomy on household decision-making, we categorized the index score into "yes" if the score is greater than 0 (i.e. women have autonomy) and "no" if the score is 0 (i.e. women do not have autonomy) $21-23$.

To include some covariates in the study, we reviewed some papers related on woman's autonomy in household decision making. We also took some other covariates in the study which were not taken in the reviewed papers as we thought these variables might have important effects on women's autonomy. The covariates included in the analysis were respondent's age at first marriage, gap between respondent's and husband's education, age difference of married couples, number of living children, respondent's current working status, wealth index, religion, husband's occupation, family size, media exposure, NGO membership, place of residence and division. The respondent's age at first marriage was not given directly in the BDHS, 2014 but there were respondent's age at first cohabitation. In the perspective of Bangladesh, respondent's age at first cohabitation and age at first marriage are same. According to a previous study ${ }^{24}$, a new variable education gap was created by taking difference between the spousal education levels which had three categories: no difference, wife with higher education and wife with lower education than husband. The wealth index variable was constructed from the data on household assets in the BDHS, 2014. We re-categorized the wealth index into poor (merging poorest and poorer), middle and rich (merging richer and richest). Religion was re-categorized into Muslims and non-Muslims. There are so many categories of husband's occupation in BDHS. Here, we recategorized the husband's occupation into farmer, labour, business, service and others. Respondent's media exposure was assessed for listening radio, watching television and reading newspaper and magazines. The media exposure was categorized into yes (if the respondent was exposed to any of the above media) and no (if she was not exposed to any of the above media). Women's NGO membership was assessed for belong to Grameen bank, BRAC, BRDB, ASHA, Proshika, mother's club and others. The NGO membership was categorized into two categories: yes (if she belongs to any of the above NGOs) and no (if she does not belong to any of the above NGOs).

Statistical Analysis
Bivariate analysis of women's autonomy at household decision making with different socio-economic and demographic variables were conducted to know whether there existed significant associations among them using chisquare test of association and analysis of variance (ANOVA) F-test. The adjusted effects of covariates on women's autonomy were obtained by performing mixed logistic regression model.

\section{Mixed Logistic Regression Model}

Generalized linear model (GLM) is extended to generalized linear mixed model (GLMM) to deal with the situations where subjects are correlated within clusters. In GLMM, a random effect is introduced with the fixed effects to account the correlation among subjects and to obtain more precise estimates of the regression coefficients.

Suppose the random variable $Y_{k i}$ is the $i^{\text {th }}(\mathrm{i}=1,2, \ldots, \mathrm{n})$ observation from $k^{t h}(\mathrm{k}=1,2, \ldots, \mathrm{p})$ cluster. Let $x_{k i}$ and $v_{k}$ be the vector of covariates with order $m \times 1$ and random component cluster, respectively. Then a mixed logistic regression model can be written using logit link as

$$
\log \left(\frac{P_{k i}}{1-P_{k i}}\right)=x_{k i}{ }^{\prime} \beta+v_{k}
$$

where $\beta=\left(\beta_{1}, \beta_{2}, \ldots, \beta_{m}\right)^{\prime}$ is the $\mathrm{m} \times 1$ vector of regression parameters and $E\left(Y_{k i} \mid x_{k i}, v_{k}\right)=P_{k i}$. In our study, we have assumed that $v_{k}$ is normally and identically distributed with mean 0 and variance $\sigma_{v}{ }^{2}$. In this set up, our interest is to find the estimates of the parameters $\beta$ and $\sigma_{v}{ }^{2}$. Statistical package STATA 14 has been used to serve this purpose.

\section{Results and Discussion}

Information are obtained from 16,545 ever-married women with current age 15-49. Among these selected women, $23.91 \%$ women married at the age of 18 years or above and the rest $76.09 \%$ women married at the age of below 18 years. About $43 \%$ of the women are from rich families while the percentages of poor and middle class women are 36.88 and 19.1, respectively. A large number of women are found to be exposed in media $(63.35 \%)$ while $36.65 \%$ are not. It is found that most of the women $(66.02 \%)$ are not involved in any of NGOs in Bangladesh whereas $33.98 \%$ women are involved to NGO. It is observed that only $30.37 \%$ women work outside home and the rest $69.63 \%$ women do not work. It is also found that highest number $(28.78 \%)$ of husbands is servicemen followed by labour $(27.85 \%)$, businessmen $(22.62 \%)$, farmers $(15.28 \%)$ and other occupations (5.44\%). Among the women included in this study, $34.05 \%$ are from urban areas, while most of them are from rural areas (65.95\%). Moreover, $83.03 \%$ women have autonomy in household decision making and $16.97 \%$ women have not.

In order to know whether the covariates are significantly associated with women's autonomy in household decision making, Pearson Chi-square and ANOVA F- tests have been employed in the study and the results are presented in Table 1 . 
Table 1. Bivariate analysis of Bangladeshi women's autonomy in household decision making with each of the background characteristics.

\begin{tabular}{|c|c|c|c|c|}
\hline \multirow[b]{2}{*}{$\begin{array}{c}\text { Background } \\
\text { characteristics }\end{array}$} & \multirow[b]{2}{*}{$\begin{array}{c}\text { Mean } \\
(\mathrm{SD})\end{array}$} & \multicolumn{2}{|c|}{$\begin{array}{l}\text { Women's } \\
\text { autonomy }\end{array}$} & \multirow[b]{2}{*}{$\mathrm{p}$-value } \\
\hline & & $\begin{array}{l}\text { No } \\
(\%)\end{array}$ & $\begin{array}{l}\text { Yes } \\
(\%)\end{array}$ & \\
\hline \multicolumn{5}{|l|}{$\begin{array}{l}\text { Age at first } \\
\text { marriage }\end{array}$} \\
\hline Age18 & & 17.1 & 82.9 & 0.671 \\
\hline Age18 & & 16.7 & 83.3 & \\
\hline $\begin{array}{l}\text { Spousal age } \\
\text { difference }\end{array}$ & $\begin{array}{c}8.96 \\
(0.04)\end{array}$ & - & - & 0.136 \\
\hline \multicolumn{5}{|l|}{ Education gap } \\
\hline No difference & & 17.5 & 82.5 & 0.018 \\
\hline Wife higher educated & & 16.7 & 83.3 & \\
\hline Wife lower educated & & 16.6 & 83.4 & \\
\hline \multicolumn{5}{|l|}{$\begin{array}{c}\text { Number of living } \\
\text { children }\end{array}$} \\
\hline No child & & 37.6 & 62.4 & $<0.001$ \\
\hline $1-2$ & & 15.8 & 84.2 & \\
\hline $2+$ & & 13.2 & 86.8 & \\
\hline \multicolumn{5}{|l|}{ Family size } \\
\hline $1-4$ & & 12.7 & 87.3 & $<0.001$ \\
\hline $5-7$ & & 17.8 & 82.2 & \\
\hline $7+$ & & 26.5 & 73.5 & \\
\hline \multicolumn{5}{|l|}{ Wealth index } \\
\hline Poor & & 18.8 & 81.2 & $<0.001$ \\
\hline Middle & & 18.2 & 81.8 & \\
\hline Rich & & 14.8 & 85.2 & \\
\hline \multicolumn{5}{|l|}{ Media Exposure } \\
\hline No & & 19.4 & 80.6 & $<0.001$ \\
\hline Yes & & 15.6 & 84.4 & \\
\hline \multicolumn{5}{|l|}{ NGO membership } \\
\hline No & & 19.2 & 80.9 & $<0.001$ \\
\hline Yes & & 12.6 & 87.1 & \\
\hline \multicolumn{5}{|l|}{$\begin{array}{l}\text { Currently working } \\
\text { status }\end{array}$} \\
\hline No & & 19.4 & 80.6 & $<0.001$ \\
\hline Yes & & 11.6 & 88.4 & \\
\hline \multicolumn{5}{|l|}{ Religion } \\
\hline Muslim & & 17.2 & 82.8 & 0.056 \\
\hline \multicolumn{5}{|l|}{$\begin{array}{l}\text { Husband's } \\
\text { occupation }\end{array}$} \\
\hline Farmer & & 17 & 83 & 0.002 \\
\hline Labour & & 17.3 & 83.1 & \\
\hline Business & & 17.3 & 82.7 & \\
\hline Service & & 15.6 & 84.4 & \\
\hline Others & & 20.4 & 79.6 & \\
\hline \multicolumn{5}{|l|}{ Place of residence } \\
\hline Urban & & 13.8 & 86.2 & $<0.001$ \\
\hline Rural & & 18.6 & 81.4 & \\
\hline Division & & & & \\
\hline Barisal & & 19.3 & 80.7 & $<0.001$ \\
\hline Chittagong & & 17.9 & 82.1 & \\
\hline
\end{tabular}

$\begin{array}{ccc}\text { Dhaka } & 16.7 & 83.3 \\ \text { Khulna } & 18.6 & 81.4 \\ \text { Rajshahi } & 14.7 & 85.3 \\ \text { Rangpur } & 14.3 & 85.7 \\ \text { Sylhet } & 23.7 & 76.3\end{array}$

All the covariates except age at first marriage, spousal age difference and religion showed unadjusted significant associations $(p<0.05)$ with women's autonomy in household decision making but religion was significant at $10 \%$ level in the bivariate analysis. The insignificant covariates women's age at first marriage and spousal age difference have been used in multivariate analysis because these covariates found as the important factors for autonomy in other studies.

In the regression analysis, all the covariates except women's religion are found to have significant effects on women's autonomy in household decision making (Table 2). Women's age at first marriage shows a strong positive association with women's autonomy. The women who married at age of 18 years or above have $20 \%$ higher odds of having participation in decision making than those who married at age of below 18 years. This is because the early married women (below 18 years) are immature and dependent on their husbands. Increase with spousal age difference is less likely to have women's autonomy in decision making. The Table 2 shows that the high educated women with respect to their husbands have $15 \%$ higher odds of having autonomy in decision making than those women whose have same education with their husbands. This is expected because the more educated women are capable of taking decisions easily. Again, the lower educated and same educated women do not have significant difference in decision making ( $p>0.10$ ). The women who have 1-2 children are 3.05 times and who have $2+$ children are 5.11 times likely to have participation in decision making compared to women with no children. It is because the children give their mothers more mental support in the family and also having children is a power of mothers. Women with 1-4 family members have $68 \%$ higher odds of participation and women with $7+$ family members have $28 \%$ lower odds of participation in household decision making compared to the women with 5-7 family members. Thus, it can be said that women with the small size family have higher autonomy in decision making. There is no significant difference $(p>0.10)$ between poor and middle class women. The rich women have $25 \%$ higher odds of having autonomy in decision making $(\mathrm{p}<0.01)$ compared to middle class women. It is expected because rich women have more access to take decisions about family matters. The Table 2 shown that media exposure women have $16 \%$ higher odds of taking decisions in household compared to women who are not media exposure $(\mathrm{p}<0.05)$. It is due to the fact that the women who are exposed in media are concerned about the world and get up to date information about health care or any other household matters. The NGO member women are more likely to participate in decision making than the non-NGO member women. This may 
happen because NGO member women are given importance by their family. Women working outside home have 53\% higher odds of having autonomy than those women who are non-worker. It is expected because working women earns money and contributes to the family. Table 2 shows that no significant difference has been observed between Muslim and non-Muslim women to participate in decision making. Women having businessmen husbands have $14 \%$ lower odds in household decision making than those women having farmer husbands.

Table 2. Adjusted odds ratios (OR) with their 95\% confidence intervals (CI) for different covariates obtained from mixed logistic regression model.

\begin{tabular}{|c|c|c|}
\hline $\begin{array}{c}\text { Background } \\
\text { characteristics }\end{array}$ & OR & $95 \% \mathrm{CI}$ of OR \\
\hline \multicolumn{3}{|l|}{ Age at first marriage } \\
\hline Age 18 & 1.00 & \\
\hline Age18 & $1.20 * * *$ & $1.07-1.33$ \\
\hline \multicolumn{3}{|l|}{ Education gap } \\
\hline \multicolumn{3}{|l|}{ No difference } \\
\hline Wife higher educated & $1.15^{* *}$ & $1.03-1.28$ \\
\hline Wife lower educated & 0.99 & $0.89-1.11$ \\
\hline \multicolumn{3}{|l|}{ Number of living children } \\
\hline No child & 1.00 & \\
\hline $1-2$ & $3.05 * * *$ & $2.69-3.46$ \\
\hline $2+$ & $5.11 * * *$ & $4.42-5.91$ \\
\hline \multicolumn{3}{|l|}{ Family size } \\
\hline $1-4$ & $1.68 * * *$ & $1.51-1.87$ \\
\hline $5-7$ & 1.00 & \\
\hline $7+$ & $0.72 * * *$ & $0.64-0.81$ \\
\hline \multicolumn{3}{|l|}{ Wealth index } \\
\hline Poor & 0.98 & $0.86-1.11$ \\
\hline Middle & 1.00 & \\
\hline Rich & $1.25 * * *$ & $1.09-1.42$ \\
\hline \multicolumn{3}{|l|}{ Media Exposure } \\
\hline No & 1.00 & \\
\hline Yes & $1.16^{* *}$ & $1.03-1.30$ \\
\hline \multicolumn{3}{|l|}{ NGO membership } \\
\hline No & 1.00 & \\
\hline Yes & $1.31 * * *$ & $1.19-1.46$ \\
\hline \multicolumn{3}{|l|}{ Working status } \\
\hline No & 1.00 & \\
\hline Yes & $1.53 * * *$ & $1.38-1.71$ \\
\hline \multicolumn{3}{|l|}{ Religion } \\
\hline Muslim & 0.90 & $0.76-1.07$ \\
\hline Non-Muslim & 1.00 & \\
\hline \multicolumn{3}{|l|}{ Husband's occupation } \\
\hline Farmer & 1.00 & \\
\hline Labour & 0.94 & $0.82-1.09$ \\
\hline Business & $0.86^{*}$ & $0.74-1.01$ \\
\hline Service & 1.05 & $0.90-1.22$ \\
\hline Others & 0.87 & $0.70-1.08$ \\
\hline \multicolumn{3}{|l|}{ Place of residence } \\
\hline Urban & $1.29 * * *$ & $1.12-1.48$ \\
\hline Rural & 1.00 & \\
\hline \multicolumn{3}{|l|}{ Division } \\
\hline Barisal & $0.70 * * *$ & $0.56-0.88$ \\
\hline Chittagong & $0.74 * * *$ & $0.60-0.92$ \\
\hline Dhaka & 1.00 & \\
\hline Khulna & $0.61 * * *$ & $0.49-0.76$ \\
\hline
\end{tabular}

\begin{tabular}{cll} 
Rajshahi & $0.80^{* *}$ & $0.64-1.00$ \\
Rangpur & 0.92 & $0.74-1.16$ \\
Sylhet & $0.57 * * *$ & $0.45-0.72$ \\
\hline Variance component & $0.25 * * *$ & \\
\hline$* * * \mathrm{p}<0.01, * * \mathrm{p}<0.05, * \mathrm{p}<0.10$ &
\end{tabular}

Moreover there is no significant difference of the women whose husbands are farmer with the women whose husbands are involved in any other occupations. The study reveals that women from the urban area have significantly greater influence (29\% higher odds) in household decision making than those who are from rural area. This is because rural women do not get enough facility like freedom of doing job, freedom of movement, education etc. It is found that women from Barisal, Chittagong, Khulna, Rajshahi and Sylhet divisions have 30\%, 26\%, 39\%, 20\% and 43\%, respectively lower odds of having autonomy in decision making compared to women from Dhaka. This may be due to fact that the women of Dhaka get enough facility like freedom of movement, freedom of doing job, education, economic freedom etc.

From the above discussion, it was found that women's age at first marriage, spousal age difference, education gap between husband and wife, number of living children, family size, wealth index, media exposure, NGO membership, working status, husband's occupation, place of residence and division were potential determinants for women's autonomy in household decision making in Bangladesh.

\section{Conclusions}

Women's autonomy to participate in the decision-making in the family is influenced by different factors. Bangladeshi women face with a great disadvantage with respect to autonomy in decision making on their own health care ${ }^{26}$. The goal of our study was to find out the potential factors that affect women's autonomy in household decision making based on BDHS, 2014 data. In the study, the mixed logistic regression model has been applied for analyzing women's autonomy to take into account the correlation among subjects within each cluster so that precise estimates of the regression parameters can be obtained. From the results, it can be concluded that decrease in marital age less than 18 and spousal age difference, as well as increase in media exposure and NGO member women will increase the women's autonomy in Bangladesh. Besides these, women with lower economic status, higher family size, less number of living children in family and living in rural areas are facing problem most to participate in household decision making. Proper steps need to be taken to increase autonomy among these particular women so that they can contribute to the family as well as society by giving their valuable opinions.

This study has some limitations. Firstly, women's autonomy was measured by taking only household decision-making variables but the other variables such as women's freedom of movement, economic freedom etc., were not included to define women's autonomy. Secondly, only women's current decision-making patterns were used 
to define autonomy but ignored past patterns, while some studies revealed that current patterns of decision-making reflect past patterns ${ }^{20}$. Thirdly, only women were asked about decision-making patterns but not asked their husbands.

\section{Acknowledgement}

We are thankful to the NIPORT, Bangladesh for allowing us to use the BDHS, 2014 data.

\section{References}

1. Narayan and Deepa, 2002. Empowerment and Poverty Reduction: World Bank.

2. Malhotra A., and Schuler SR, 2002. Women's empowerment as a variable in international development. Gender and development group: World Bank.

3. Dyson, T. and M. Moore, 1983. On kinship structure, female autonomy, and demographic behavior in India. Population and development Review. 9, 35-60.

4. Agarwal, B., 1994. A Field of One's Own: Gender and Land Rights in South Asia. Cambridge University Press.

5. Bloom SS., Wypij D, and Gupta MD, 2001. Dimensions of women's autonomy and the influence on maternal health care utilization in a north Indian city. Demography journal. 38, 67-78.

6. Haque M. M., T. M. Islam, M. I. Tareque and M. G. Mostofa, 2011. Women Empowerment on Autonomy: A Comparative View in Bangladesh Context. Bangladesh Journal of Sociology. 8, 2.

7. Haider, R. M., Z. P. Qureshi and M. M. Khan, 2017. Effects of women's autonomy on maternal healthcare utilization in Bangladesh: Evidence from a national survey. Sexual \& Reproductive Healthcare. 14, 40-47.

8. Kamal, N., 2007. Determinants of contraceptive use among women workers in the urban slums of Bangladesh. International Conference in United Kingdom.

9. Cleland, J., N. Kamal and A. Sloggett, 1996. Links between fertility regulation and the schooling and autonomy of women in Bangladesh in South Asia. Sage Publications.

10. Rahman, M. M., M. G. Mostofa and M. A. Hoque, 2014. Women's household decision-making autonomy and contraceptive behavior among Bangladeshi women. Sexual \& Reproductive Healthcare. 5(1), 9-15.

11. Biswas, K. A., T. A. Shovo, M. Aich and S. Mondol, 2017. Women's autonomy and control to exercise reproductive rights: A sociological study from rural Bangladesh. SAGE Open, 1-10.

12. Woldemicael G., 2007. Women with higher autonomy seek more maternal and child health-care: Evidence from Ethiopia and Eritrea.

13. Dangal G, Bhandari TR, 2014. Women's autonomy: new paradigm in maternal health care utilization. Global journal of medicine and public helath. 3, 1-2.

14. Anderson S. and M. Eswaran, 2009. Determinates of female autonomy: Evidence from Bangladesh. Journal of Development Economics. 90, 179-191.
15. Mistry, R., O. Galal and M. Lu, 2009. Women's autonomy and pregnancy care in rural India: A contextual analysis. Social Science \& Medicine. 69, 926-933.

16. Kamiya, Y., 2011. Women's autonomy and reproductive health care utilization: Empirical evidence from Tajikistan. Journal of Health policy. 102, 304-313.

17. Bloom S., D. Wypij and D. Gupta, 2001. Dimensions of women's autonomy and the influence on maternal health care utilization in a northern Indian city. Demography journal. 38(1), 67-78.

18. Carlson, J. G., K. Kordas and L. E. Murry-kolb, 2015. Associations between women's autonomy and child nutritional status: a review of the literature. Maternal \& child nutrition. 11(4), 452-82.

19. Nigatu, D., A. Gebremariam, M. Abera, T. Setegn and K. Deribe. 2014. Factors associated with women's autonomy regarding maternal and child health care utilization in Bale zone: a community based cross-sectional study. BMC Women's Health. 14: 79.

20. Hindin, J. M., 2000. Women's autonomy, women's status and fertility-related behavior in Zimbabwe. Population Research and Policy Review. 19(3), 255-282.

21. Rahman, M., 2012. Women's autonomy and unintended pregnancy among currently pregnant women in Bangladesh. Maternal child health. 16, 1206-1214.

22. Kishor, S. and L. Subaiya, 2008. Understanding Women's Empowerment: A Comparative Analysis of DHS.

23. Ghenet, B. and R. Amira, 2014. The relationship between female genital cutting and women's autonomy in Eritrea. Journal of Gynecology and Obstetrics. 74(2), 174-185.

24. Daniel R., Z. M. Beate, K. H. Mobarak, P. Thorsten and K. Alexander, 2012. Association between gap in spousal education and domestic violence in India and Bangladesh. BMC Public Health. 12:467.

25. Bangladesh Demographic and Health Survey (BDHS), 2014. National Institute of Population Research and Training (NIPORT) of the Ministry of Health and Family Welfare. ICF International of Rockville, Maryland, USA and Dhaka, NIPORT, Mitra and Associates.

26. Senarath, U. and N. S. Gunawardena, 2009. Women's Autonomy in Decision Making for Health Care in South Asia. Asia Pacific Journal of Public Health. 21: 137. 
